\title{
A Guide RNA Sequence Design Platform for the CRISPR/Cas9 System for Model Organism Genomes
}

\author{
Ming Ma, ${ }^{1}$ Adam Y. Ye, ${ }^{2,3}$ Weiguo Zheng, ${ }^{4}$ and Lei Kong ${ }^{2}$ \\ ${ }^{1}$ Biomedical Engineering Department, College of Engineering, Peking University, Beijing 100871, China \\ ${ }^{2}$ Center for Bioinformatics, State Key Laboratory of Protein and Plant Gene Research, School of Life Sciences, Peking University, \\ Beijing 100871, China \\ ${ }^{3}$ National Institute of Biological Sciences, 7 Science Park Road, Zhongguancun Life Science Park, Beijing 102206, China \\ ${ }^{4}$ Institute of Computer Science and Technology, Peking University, Beijing 100871, China
}

Correspondence should be addressed to Lei Kong; kongl@mail.cbi.pku.edu.cn

Received 4 July 2013; Accepted 13 September 2013

Academic Editor: Yi Zhao

Copyright (C) 2013 Ming Ma et al. This is an open access article distributed under the Creative Commons Attribution License, which permits unrestricted use, distribution, and reproduction in any medium, provided the original work is properly cited.

Cas9/CRISPR has been reported to efficiently induce targeted gene disruption and homologous recombination in both prokaryotic and eukaryotic cells. Thus, we developed a Guide RNA Sequence Design Platform for the Cas9/CRISPR silencing system for model organisms. The platform is easy to use for gRNA design with input query sequences. It finds potential targets by PAM and ranks them according to factors including uniqueness, SNP, RNA secondary structure, and AT content. The platform allows users to upload and share their experimental results. In addition, most guide RNA sequences from published papers have been put into our database.

\section{Introduction}

Gene engineering technology has always been a hot topic in life science research. With the development of gene modification technology, certain genes can be knocked out or knocked down to a lower level. The appearance of zinc finger nuclease (ZFN) and tale nuclease (TALEN) has greatly accelerated progress in this field, but their efficiency is often unpredictable and it is difficult to target selected genes [1-8].

Recently, Cas9/CRISPR has been reported to successfully induce targeted gene disruption and homologous recombination in both prokaryotic and eukaryotic cells with higher efficiency compared with ZFN and TALEN [9-13]. Additionally, it is easier to design guide sequence and easy to use for Cas9/CRISPR system [10]. This novel technology will be of great potential for application in both research field and clinical trials.

However, there is no available tool for the guide RNA design of Cas9/CRISPR silencing system. Although Mali et al. have reported the construction of unique whole human genome guide RNA library, covering more than $40 \%$ human exons [9], they did not provide a tool for researchers to design novel target sequences for other model organisms.

Existed library also did not take into consideration related influencing factors, such as SNP, deletion or insertion on the genome, and potential RNA secondary structure. According to our current understanding of the gRNA maturing process, the secondary structure of gRNA is crucial for Cas9-gRNA complex [14]. The $20 \mathrm{bp}$ guide RNA sequence is used to bind with target site in genomes. If they are mostly involved into RNA loops, the efficiency to bind with target sites would be low. Thus, this factor should be taken into consideration. Besides, the interference efficiency is probably closely related to the melting temperature of the gRNA-DNA hybrid. A relatively high AT content is negatively correlated with the off-target effect, and thus sequence with extremely low AT percentage is, to some extent, not recommended [9].

Thus, we developed an online platform for the guide RNA design of the Cas9/CRISPR silencing system (http://cas9.cbi.pku.edu.cn/), with DNA variants information integrated. This tool helps researchers design their candidate guide RNA sequences more easily and provides assistance 


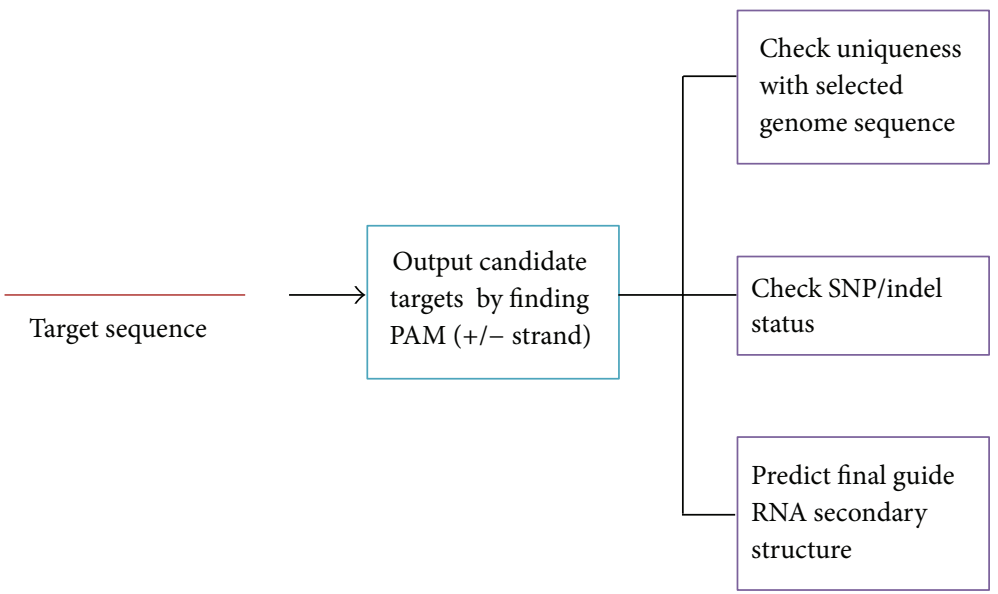

FIGURE 1: Streamline of guide RNA design platform. Target sequences are searched for the whole genome for uniqueness, and then check $\mathrm{SNP} /$ indel status. The results are output from top to bottom with more unique and fewer SNP/indel. The entire gRNA secondary structure is also given as reference.

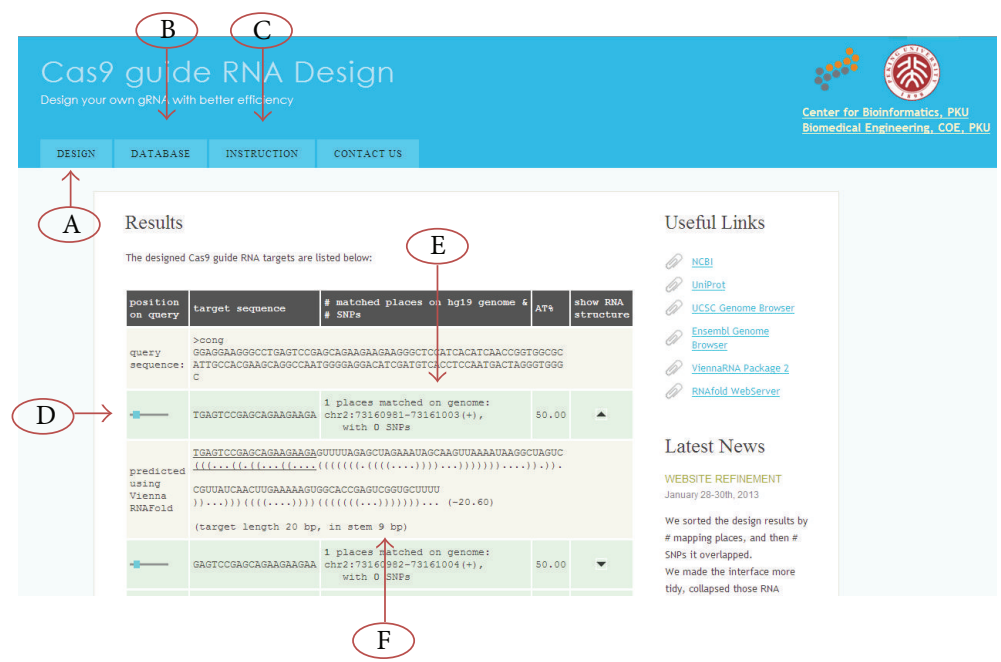

FIGURE 2: Instruction of platform function. Overview of platform interface. (A)-(C) represent functions and database. (D) represents sense/antisense and position information of output sequences on target sequences. (E) represents uniqueness and SNP/indel status. (F) represents mature gRNA secondary structure.

for users to choose better candidates based on preliminary results.

\section{Materials and Methods}

Both guide RNA sequences and their corresponding efficiency were manually collected from the literature and stored in our database. For designing guide RNA, we used a Java framework mainly containing 5 steps, and connecting to Tomcat web server.

In the first step, the program would find any candidate sequences based on the $\mathrm{N}_{20}$ NGG sequence pattern principle, where NGG represents PAM sequence, by utilizing Java regular expression matching. In the second step, the program would put all the candidate sequences to a fasta file and run bowtie 0.12 .9 to check if they could be mapped on selected model organism's genome uniquely [15]. The parameters for bowtie were "-f-v 1-k $10-116-S$," as "-f” told bowtie the input was fasta file, “-v 1" for only allowing at most one mismatch, “-k 10 " reporting up to 10 good alignments, “-1 16" setting seed length to 16 , and "-S" outputting sam format. As the length of target region was only $23 \mathrm{bp}$, the default seed length 28 for bowtie was not proper for this job, so we adjusted it to 16 . We thought the number of mismatches might largely affect effectiveness, and this step mainly focused on checking the mapping uniqueness, so we just looked for hits with at most one mismatch and output at most 10 hits. The mapping result would be parsed in Java, and then, in the third step, would call tabix 0.2.5 to find out any overlapped SNPs or indels as reported in dbSNP135 [16-18], if the target genome was human hg19. The dbSNP135 vcf file was downloaded from GATK bundle. In the fourth step, it would predict RNA 
TABLE 1: Analyze of reported targets in human cells in this platform.

\begin{tabular}{|c|c|c|c|c|c|c|c|}
\hline Target genes & Guide RNA sequences & Mapping and SNP & $\begin{array}{l}\text { bp in } \\
\text { loops }\end{array}$ & $\mathrm{AT} \%$ & Efficiency & Methods & Reference \\
\hline $\begin{array}{l}\text { Human } \\
\text { PVALB }\end{array}$ & ATTGGGTGTTCAGGGCAGAG & $\begin{array}{l}1 \text { places matched on genome: } \\
\text { chr22:37196884-37196906(+), with } 1 \\
\text { SNPs: rs12483924 (2 bp to } 3^{\prime} \text { end) }\end{array}$ & 6 & $45 \%$ & $6.50 \%$ & \multirow{3}{*}{ Surveyor } & \multirow{3}{*}{$\begin{array}{l}\text { Cong et al. } \\
2013[10]\end{array}$} \\
\hline $\begin{array}{l}\text { Human } \\
P V A L B\end{array}$ & GTGGCGAGAGGGGCCGAGAT & $\begin{array}{l}\text { 1 places matched on genome: } \\
\text { chr22:37196866-37196888(+), with } 3 \\
\text { SNPs: rs3484 (18 bp to } 3^{\prime} \text { end) } \\
\text { rs181855770 (10 bp to } 3^{\prime} \text { end) } \\
\text { rs9607383 ( } 9 \text { bp to } 3^{\prime} \text { end) }\end{array}$ & 9 & $30 \%$ & $N D$ & & \\
\hline $\begin{array}{l}\text { Human } \\
\text { PVALB }\end{array}$ & GGGGCCGAGATTGGGTGTTC & $\begin{array}{l}\text { 1 places matched on genome: } \\
\text { chr22:37196875-37196897(+), with } 2 \\
\left.\text { SNPs: rs181855770 (19 bp to } 3^{\prime} \text { end }\right) \\
\text { rs } 9607383\left(18 \text { bp to } 3^{\prime} \text { end }\right)\end{array}$ & 9 & $35 \%$ & ND & & \\
\hline $\begin{array}{l}\text { Human } \\
\text { AAVS1 }\end{array}$ & GGGGCCACTAGGGACAGGAT & $\begin{array}{c}1 \text { places matched on genome: } \\
\text { chr19:55627117-55627139(-), with } 0 \\
\text { SNPs }\end{array}$ & 8 & $35 \%$ & $8.07 \%$ & \multirow[b]{2}{*}{ HR } & \multirow[b]{2}{*}{$\begin{array}{l}\text { Mali et al. } \\
2013 \text { [9] }\end{array}$} \\
\hline $\begin{array}{l}\text { Human } \\
\text { AAVS1 }\end{array}$ & GТССССТССАССССАСАGТG & $\begin{array}{l}2 \text { places matched on } \\
\text { genome:chr19:55627136- } \\
\text { 55627158(-), with 0 SNP } \\
\text { schr4:108975634-108975656(+), with } \\
\text { 1 SNPs: rs115503552 (7 bp to 3' end) }\end{array}$ & 7 & $30 \%$ & $3.26 \%$ & & \\
\hline $\begin{array}{l}\text { Human } \\
\text { VEGFA }\end{array}$ & GGGTGGGGGGAGTTTGCTCC & $\begin{array}{l}\text { 1 places matched on genome: } \\
\text { chr6:43737291-43737313(-), with } 1 \\
\left.\text { SNPs: rs12210204 (1 bp to } 3^{\prime} \text { end }\right)\end{array}$ & 11 & 30 & $26 \%$ & \multirow{3}{*}{ T7EI assay } & \multirow{3}{*}{$\begin{array}{l}\text { Fu et al. } \\
2013[21]\end{array}$} \\
\hline $\begin{array}{l}\text { Human } \\
\text { VEGFA }\end{array}$ & GACССССТССАССССGССТС & $\begin{array}{c}1 \text { places matched on genome: } \\
\text { chr6:43738556-43738578(-), with } 0 \\
\text { SNPs }\end{array}$ & 4 & 20 & $50 \%$ & & \\
\hline $\begin{array}{l}\text { Human } \\
\text { VEGFA }\end{array}$ & GGTGAGTGAGTGTGTGCGTG & $\begin{array}{c}1 \text { places matched on genome: } \\
\text { chr6:43737454-43737476(+), with } 0 \\
\text { SNPs }\end{array}$ & 12 & 40 & $49.40 \%$ & & \\
\hline
\end{tabular}

${ }^{*} \mathrm{ND}$ represents not detectable. Italic font represents low efficient gRNAs within the same gene group.

secondary structures for those candidate gRNA sequences by calling Vienna RNAfold 2.0.7 with default parameters [19]. In the last step, the program rearranged all the information for the designed gRNA and formatted it to better-looking HTML. The AT\% and the distance of the variants to the $3^{\prime}$ end of the target region were also calculated. The output gRNAs were sorted by both number of mapping hits and number of overlapping SNPs. The time consumption for this pipeline was mainly on running bowtie and sometimes tabix, when there existed many target sequences, and was roughly about three seconds for one query sequence.

\section{Results and Discussion}

Multiple gene sequences are allowed for batch gRNA design and the streamline of this platform is shown in Figure 1. The results contain genomic loci information of gRNAs and SNP/INDEL inside them. This would help researchers choose a more unique target candidate and avoid $\mathrm{SNP}$ /insertion/deletion. Moreover, this platform evaluates all candidates based on their RNA secondary structure and AT content, allowing users to choose better candidates (Figure 2).

Recently, Jiang et al. report that only the first six base pairs near PAM are of great importance for recognition efficiency in bacteria [20]. It is unknown whether or not this is still the case for eukaryotic or even mammalian cells. We will keep updating our algorithm to rank candidate gRNAs.

We conducted a validation by using those reported results in our platform on factors, such as uniqueness, SNP, and base in loops (Table 1, italic font represents low efficient targets). The more unique, with fewer SNPs and base in loops, generally the gRNA is more efficient. For the given gene $P V A L B$, the first target sequence is $50 \%$ more efficient than the rest two, since the first has 0 SNP while the rest have 3 or 2 SNPs. The first target sequence has fewer base pairs involved in RNA secondary structure loops, allowing it to bind more with target genome, while the rest two both have 9 base pairs in loops. For the given gene AAVS1, the first target is more than twofold efficient than the other, since the other one has 
an off-target site in genomes. For the given gene VEGFA, the first one is about half efficient with the rest two, since it has 1 SNP while the rest have none.

AT content is crucial factor as those previously mentioned, since evidence is not clear. Thus, we list it here as a consideration for users.

\section{Conclusions}

Our platform is an easy-to-use software to identify potential efficient gRNA sites within given sequences for model organisms, avoiding off-target effects and SNPs. This platform also allows users to search existing guide RNA/protospacer sequences and share their results. We have manually extracted most reported gRNA/protospacer sequences into our database for reference and will expand it with newly published work.

\section{Disclosure}

The online platform, database, and document are available at http://cas9.cbi.pku.edu.cn/.

\section{Authors' Contribution}

Ming Ma and Adam Y. Ye contributed equally to this work. Ming Ma conceived the idea and Adam Y. Ye, Weiguo Zheng conducted programming and website construction. Lei Kong supervised the whole job and give guidance. Ming Ma, Adam Y. Ye, and Lei Kong drafted the paper.

\section{References}

[1] J. C. Miller, M. C. Holmes, J. Wang et al., "An improved zincfinger nuclease architecture for highly specific genome editing," Nature Biotechnology, vol. 25, no. 7, pp. 778-785, 2007.

[2] J. D. Sander, E. J. Dahlborg, M. J. Goodwin et al., "Selectionfree zinc-finger-nuclease engineering by context-dependent assembly (CoDA)," Nature Methods, vol. 8, no. 1, pp. 67-69, 2011.

[3] M. Christian, T. Cermak, E. L. Doyle et al., "Targeting DNA double-strand breaks with TAL effector nucleases," Genetics, vol. 186, no. 2, pp. 756-761, 2010.

[4] J. C. Miller, S. Tan, G. Qiao et al., "A TALE nuclease architecture for efficient genome editing," Nature Biotechnology, vol. 29, no. 2, pp. 143-148, 2011.

[5] D. Reyon, S. Q. Tsai, C. Khayter, J. A. Foden, J. D. Sander, and J. K. Joung, "FLASH assembly of TALENs for high-throughput genome editing," Nature Biotechnology, vol. 30, no. 5, pp. 460$465,2012$.

[6] L. Tesson, C. Usal, S. Menoret et al., "Knockout rats generated by embryo microinjection of TALENs," Nature Biotechnology, vol. 29, no. 8, pp. 695-696, 2011.

[7] C. Tong, G. Huang, C. Ashton, H. Wu, H. Yan, and Q. L. Ying, "Rapid and cost-effective gene targeting in rat embryonic stem cells by TALENs," Journal of Genetics and Genomics, vol. 39, no. 6, pp. 275-280, 2012.

[8] J. D. Sander, L. Cade, C. Khayter et al., "Targeted gene disruption in somatic zebrafish cells using engineered TALENs," Nature Biotechnology, vol. 29, no. 8, pp. 697-698, 2011.
[9] P. Mali, L. Yang, K. M. Esvelt et al., "RNA-guided human genome engineering via Cas9," Science, vol. 339, no. 6121, pp. 823-826, 2013.

[10] L. Cong, F. A. Ran, D. Cox et al., "Multiplex genome engineering using CRISPR/Cas systems," Science, vol. 339, no. 6121, pp. 819823, 2013.

[11] M. Villion and S. Moineau, "The double-edged sword of CRISPR-Cas systems," Cell Research, vol. 23, no. 1, pp. 15-17, 2013.

[12] H. Wang, H. Yang, C. S. Shivalila et al., "One-step generation of mice carrying mutations in multiple genes by CRISPR/Casmediated genome engineering," Cell, vol. 153, no. 4, pp. 910-918, 2013.

[13] N. Chang, C. Sun, L. Gao et al., "Genome editing with RNAguided Cas9 nuclease in zebrafish embryos," Cell Research, vol. 23, no. 4, pp. 465-472, 2013.

[14] K. S. Makarova, D. H. Haft, R. Barrangou et al., "Evolution and classification of the CRISPR-Cas systems," Nature Reviews Microbiology, vol. 9, no. 6, pp. 467-477, 2011.

[15] B. Langmead, C. Trapnell, M. Pop, and S. L. Salzberg, "Ultrafast and memory-efficient alignment of short DNA sequences to the human genome," Genome Biology, vol. 10, no. 3, article R25, 2009.

[16] H. Li, "Tabix: fast retrieval of sequence features from generic TAB-delimited files," Bioinformatics, vol. 27, no. 5, pp. 718-719, 2011.

[17] S. T. Sherry, M.-H. Ward, M. Kholodov et al., "DbSNP: the NCBI database of genetic variation," Nucleic Acids Research, vol. 29, no. 1, pp. 308-311, 2001.

[18] A. McKenna, M. Hanna, E. Banks et al., “The genome analysis toolkit: a MapReduce framework for analyzing next-generation DNA sequencing data," Genome Research, vol. 20, no. 9, pp. 1297-1303, 2010.

[19] R. Lorenz, S. H. Bernhart, C. Höner Zu Siederdissen et al., "ViennaRNA package 2.0," Algorithms for Molecular Biology, vol. 6, no. 1, article 26, 2011.

[20] W. Jiang, D. Bikard, D. Cox, F. Zhang, and L. A. Marraffini, "RNA-guided editing of bacterial genomes using CRISPR-Cas systems," Nature Biotechnology, vol. 31, no. 3, pp. 233-239, 2013.

[21] Y. Fu, J. A. Foden, C. Khayter et al., "High-frequency off-target mutagenesis induced by CRISPR-Cas nucleases in human cell," Nature Biotechnology, vol. 31, pp. 822-826, 2013. 

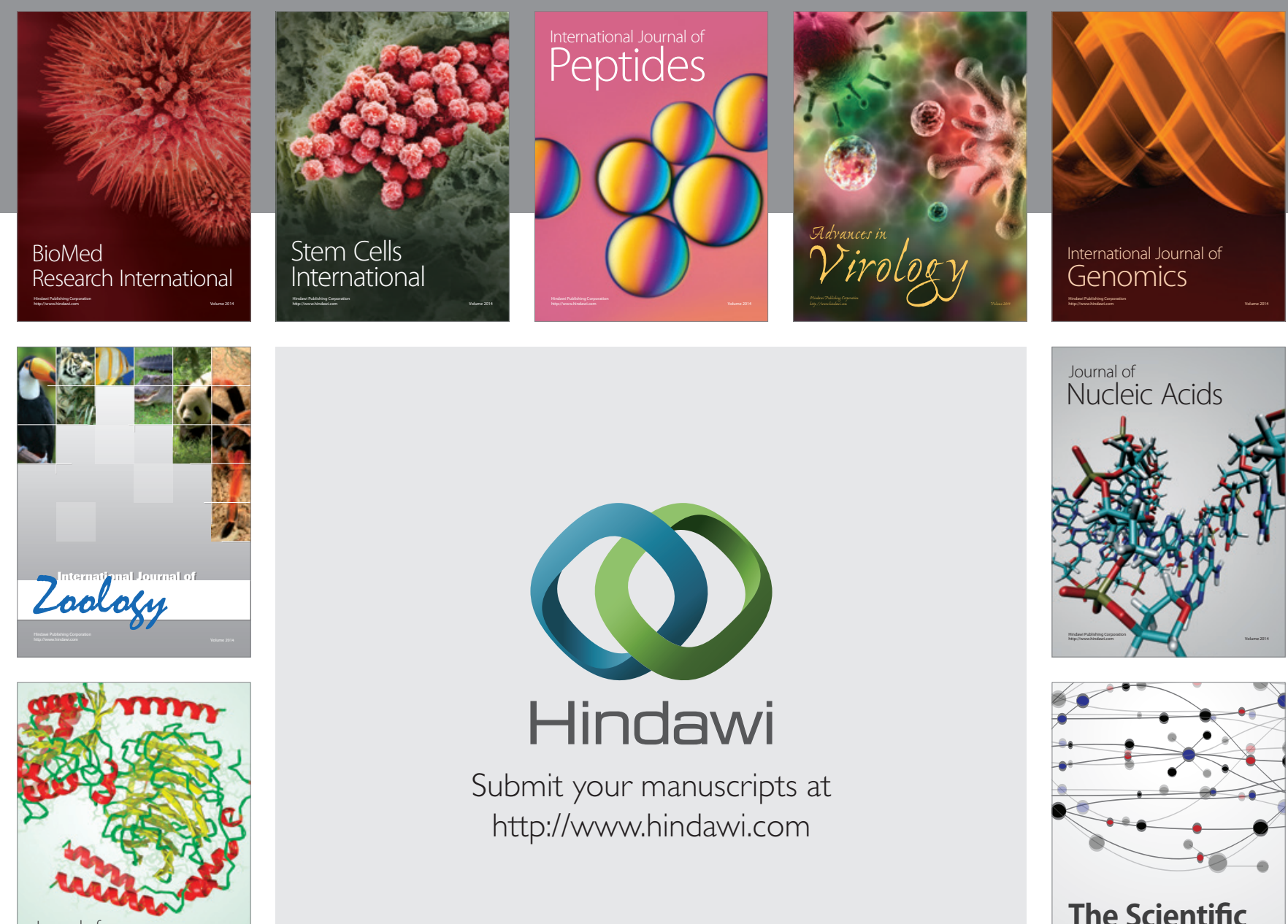

Submit your manuscripts at

http://www.hindawi.com

Journal of
Signal Transduction
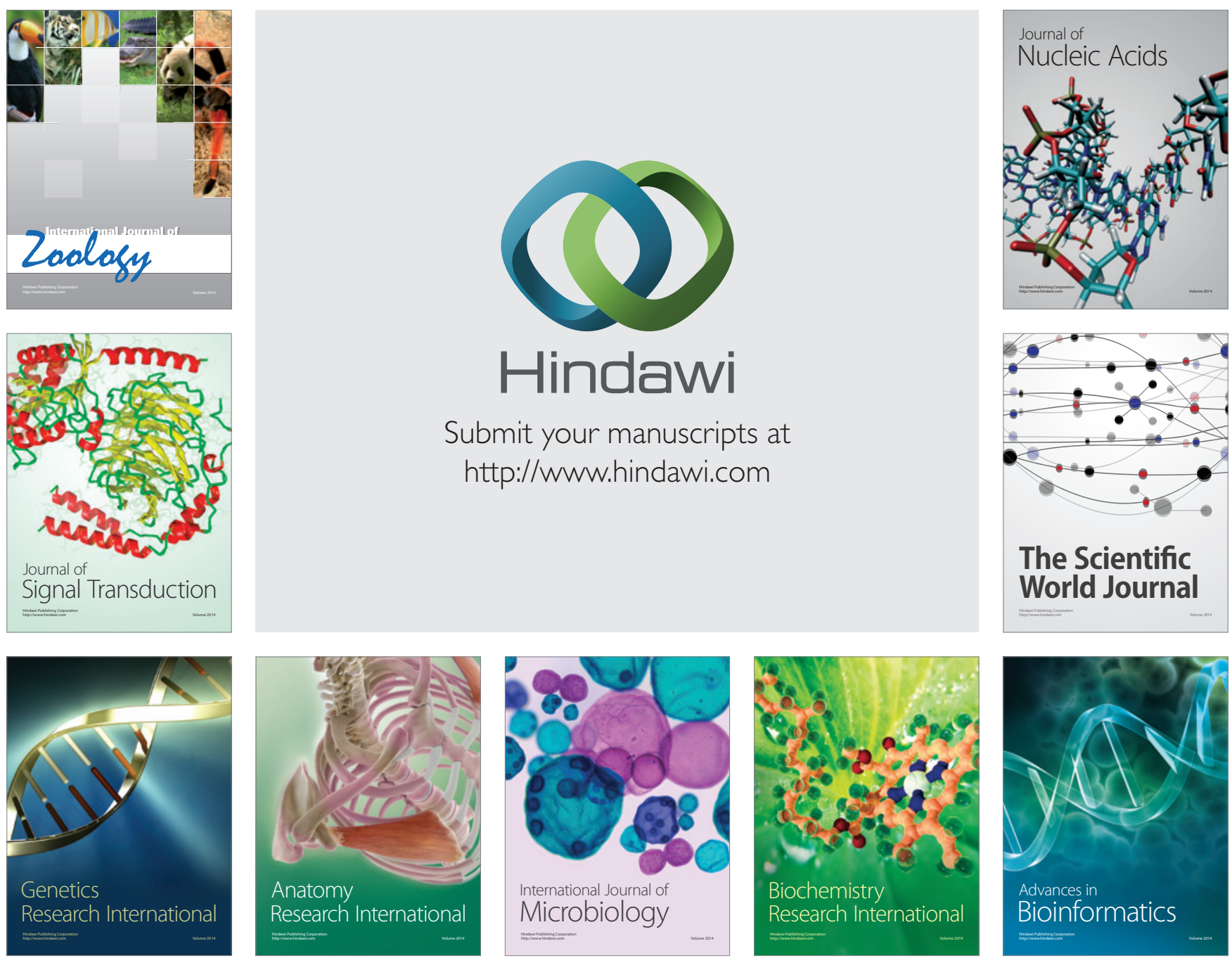

The Scientific World Journal
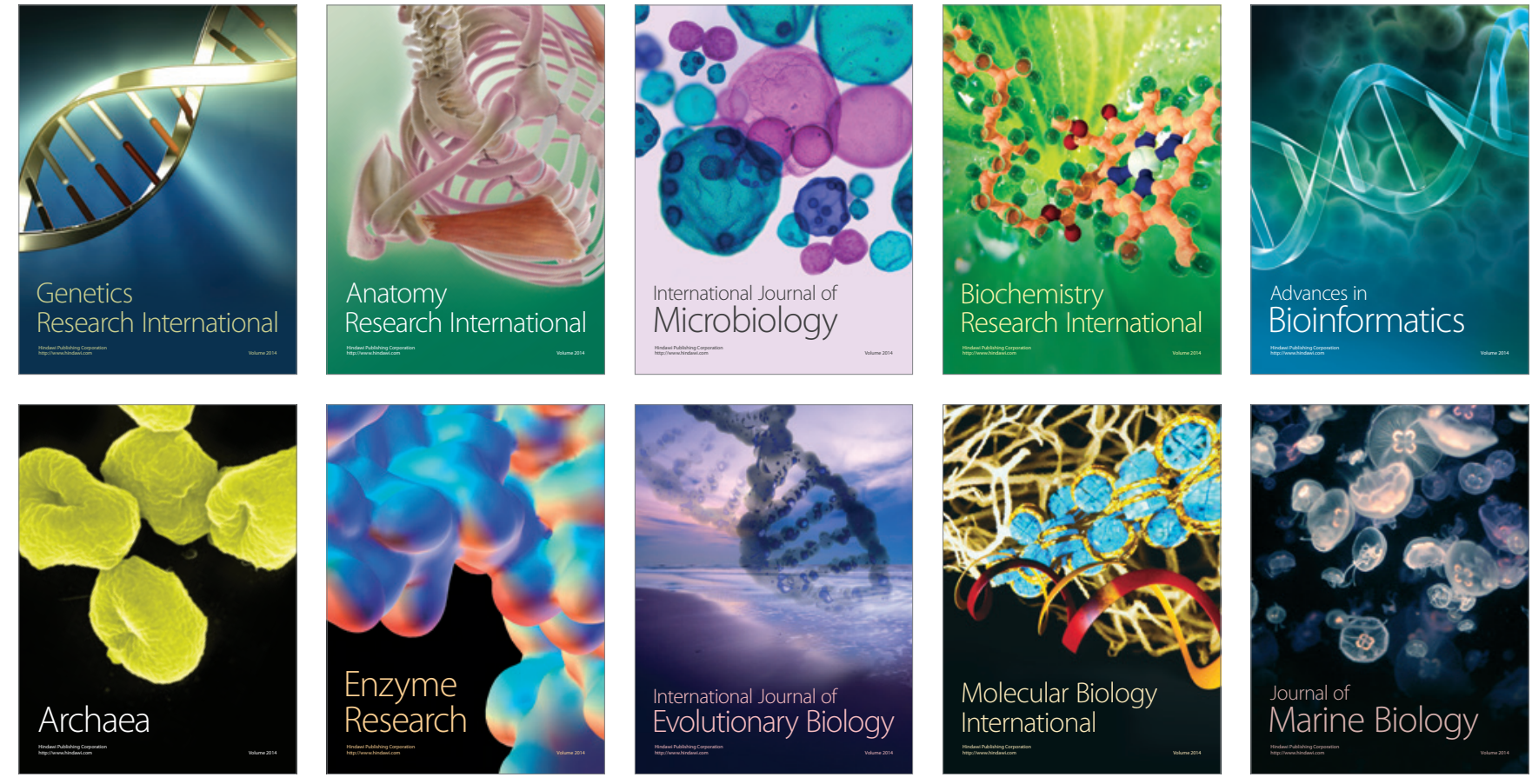